\title{
Biological Activity of an Essential Oil Blend in Human Dermal Fibroblasts
}

\author{
Xuesheng Han, Tyler Bahr* \\ dōTERRA International LLC, 389 S. 1300 W. Pleasant Grove, UT 84062, USA \\ tbahr@doterra.com
}

Abstract: Research on the biological activities of essential oilsin human skin cells is limited. This study first analyzed the effect of an essential oil blend (EOB) on 17 important protein biomarkers in cytokine-stimulated human dermal fibroblasts. The EOB was composed of essential oils of frankincense resin, sweet orange peel, litsea fruit, thyme plant, clove bud, summer savory plant, and niaouli leaf. The results showed that EOB had excellent antiproliferative activity. It significantly increased vascular cell adhesion molecule 1 levels and slightly increased the monocyte chemoattractant protein 1 and epidermal growth factor receptor production. We then studied the effect of the EOB on the expression levels of 21,224 genes in the same cells. We found that the EOB markedly affected genome-wide gene expression. Further analysis revealed that the EOB pleiotropically regulated multiple signaling pathways in human cells including hepatic fibrosis activation, antigen presentation, mitotic roles of the polo-like kinase, and cyclin and cell cycle regulation. Many pathways significantly affected by the EOB are closely related to inflammatory and immune responses. The results suggest that the EOB may affect biological processes and global gene expression in human skin cells. Further research into the underlying mechanism of action of the EOB is needed.

Keywords: Essential oil; frankincense; sweet orange; litsea; thyme; inflammation; immune response; signaling pathway; tumor; genome-wide gene expression

\section{INTRODUCTION}

Essential oils are complex mixtures of aromatic compounds naturally produced in plants. They have been used historically as well as currently for treating a variety of diseases and maintaining health in humans (Lv et al., 2013; Perry \& Perry, 2006). Recent pre-clinical and clinical studies have provided evidence supporting the benefits of essential oils to human health (Kozioł et al., 2014; Navarra et al., 2015), resulting in a wider acceptance and use of essential oils in the US and worldwide. Despite this trend, very few studies have elucidated the mechanisms of action of essential oils inhuman cells.

Thousands of distinct terpene compounds have been identified in essential oils, many of which are known for possessing diverse biological activities. Because every essential oil is primarily composed of a unique mixture of just a few of these compounds, it is hypothesized that each oilhas its own unique array of biological activities. For example, Oregano essential oil is known to have powerful anti-fungal and anti-microbial effects due to its high phenylpropene content, while Lavender's main constituents, linalool and linalyl acetate, are known to calm the CNS by activating GABAA receptors.

The tendency for essential oil compounds to exhibit synergy and antagonism is another phenomenon that is receiving growing attention. A recent study on membrane dynamics suggested that the ratios of constituents might affect an oil's activity just as much as the identity of the constituents (Hac-Wydro et al., 2017). The possibility of synergy and antagonism has sparked an interest in blending, or creating mixtures of essential oils, to achieve an oil combination with novel effects. Therefore, we studied the biological effect of an industrial essential oil blend (EOB)on a human skin disease model, the HDF3CGF pre-inflamed dermal fibroblast system, which we have used previously to study the effects of individual essential oils. The current findings will allow www.arjonline.org

Page 1 
comparison of this blend's activity with that of the individual essential oils and possibly other blends, aiding in future research on synergy, antagonism, and additive effects of essential oil blends.

The EOB contains a mixture of essential oils from frankincense (Boswellia carterii, Boswellia frereana, and Boswelliasacra) resin, sweet orange (Citrus sinensis) peel, listea (Litsea cubeba) fruit, thyme (Thymus vulgaris) plant, clove (Eugenia caryophyllata) bud, the summer savory (Satureja hortensis) plant, and niaouli (Melaleuca quinquinervia) leaf. Although many of these individual essential oils and their active constituents are known to have various therapeutic benefits, this was the first study to examine the effect of a commercial blend of these oils on human genome-wide gene expression in the HDF3CGF model system. We also studied the EOB's effect on biomarkers related to inflammation, immune responses, and tissue remodeling.

\section{Materials and Methods}

All experiments were conducted using a biologically multiplexed activity profiling (Bio MAP) system HDF3CGF designed to model the pathology of chronic inflammation robustly and reproducibly. The system comprised three components: a cell type, stimuli to create the disease environment, and a set of biomarker (protein) readouts to examine the treatment effects on the disease environment (Berg et al., 2010). The methodologies used in this study were essentially the same as those previously described (Han \& Parker, 2017a, 2017b; Kunkel et al., 2004).

\section{Reagents}

The EOB (dōTERRA, Pleasant Grove, UT, USA) was diluted in dimethyl sulfoxide (DMSO) to $8 \times$ the specified concentrations (final DMSO concentration was no more than $0.1 \%$ ). Then, $25 \mu \mathrm{L}$ of each $8 \times$ solution was added to the cell culture to a final volume of $200 \mu \mathrm{L}$ whileDMSO $(0.1 \%)$ served as the vehicle control.

The composition of the EOB was as follows: frankincense (a mixture of B. carterii, B. frereana, and B. sacra) resin oil, sweet orange ( $C$. sinensis) peel oil, litsea (Litsea cubeba) fruit oil, thyme (T. vulgaris) plant oil, clove ( $E$. caryophyllata) bud oil, summer savory (S. hortensis) plant oil, and niaouli (M. quinquinervia) leaf oil. The exact percentage composition is proprietary to the supplying company. Aromatic compounds distilled from the plant material comprised $100 \%$ of the EOB. Each essential oil originated from a country where the plant is grown. The essential oils were shipped to the US, where they were blended into the EOB. Gas chromatographymass spectrometry analysis of the EOB showed that it contained $23-27 \%$ limonene, $11-14 \%$ alphapinene, 6-8\% eugenol, 6-8\% thymol, 5-7\% carvacrol, 5-7\% eucalyptol, 4-6\% gamma-terpinene, and smaller amounts of other aromatic compounds.

\section{Cell Cultures}

Primary human neonatal fibroblasts were prepared as previously described (Bergamini et al., 2012) and were plated under low-serum conditions $(0.125 \%$ fetal bovine serum) for $24 \mathrm{~h}$. Then, the cell culture was stimulated with a mixture of interleukin (IL)-1 $\beta$, tumor necrosis factor (TNF)- $\alpha$, interferon (IFN)- $\Upsilon$, basic fibroblast growth factor (bFGF), epidermal growth factor (EGF), and platelet-derived growth factor (PDGF) for another $24 \mathrm{~h}$. The cell culture for the HDF3CGF assays was performed in a 96-well plate,and the stimulation conditions were described in detail elsewhere (Bergamini et al., 2012; R Development Core Team, 2011).

\section{Protein-Based Readouts}

An enzyme-linked immunosorbent assay (ELISA) was used to measure the biomarker levels of cell-associated and cell membrane targets. Soluble factors in the supernatants were quantified using either homogeneous time-resolved fluorescence detection, bead-based multiplex immunoassay, or capture ELISA. The adverse effects of the test agents on cell proliferation and viability (cytotoxicity) were measured using the sulforhodamine B (SRB) assay. For proliferation as says, the cells were cultured and measured after $72 \mathrm{~h}$, which is optimal for the HDF3CGF system, and the detailed procedure was described in a previous study (Bergamini et al., 2012). The measurements were performed in triplicate wells, and a glossary of the biomarkers used in this study is provided in Supplementary Table S1. 
Biological Activity of an Essential Oil Blend in Human Dermal Fibroblasts

Table S1. Glossary of Biomarkers of the Human Dermal Fibroblast System HDF3CGF Used in the Study

\begin{tabular}{|c|c|}
\hline Readout & Description \\
\hline CCL2/MCP-1 & $\begin{array}{l}\text { MCP-1 system is a chemokine that mediates recruitment of monocytes and T cells into sites } \\
\text { of inflammation. MCP-1 is categorized as an inflammation-related activity in the HDF3CGF } \\
\text { system modeling Th1 inflammation involved in wound healing and matrix remodeling. }\end{array}$ \\
\hline CD106/VCAM-1 & $\begin{array}{l}\text { VCAM- } 1 \text { is a cell adhesion molecule that mediates adhesion of monocytes and T cells to } \\
\text { endothelial cells. VCAM- } 1 \text { is categorized as an inflammation-related activity. }\end{array}$ \\
\hline CD54/ICAM-1 & $\begin{array}{l}\text { ICAM-1 is a cell adhesion molecule that mediates leukocyte-endothelial cell adhesion } \\
\text { and leukocyte recruitment. ICAM-1 is categorized as an inflammation-related activity. }\end{array}$ \\
\hline Collagen I & $\begin{array}{l}\text { Collagen I is involved in tissue remodeling and fibrosis, and is the most common fibrillar } \\
\text { collagen that is found in skin, bone, tendons and other connective tissues. Collagen I is } \\
\text { categorized as a tissue remodeling-related activity. }\end{array}$ \\
\hline Collagen III & $\begin{array}{l}\text { Collagen III is an extracellular matrix protein and fibrillar collagen found in extensible con- } \\
\text { nective tissues (skin, lung and vascular system) and is involved in cell adhesion, cell migra- } \\
\text { tion, tissue remodeling. Collagen III is categorized as a tissue remodeling-related activity. }\end{array}$ \\
\hline CXCL10/IP-10 & $\begin{array}{l}\text { IP-10 is a chemokine that mediates T cell, monocyte and dendritic cell chemotaxis. IP-10 } \\
\text { is categorized as an inflammation-related activity. }\end{array}$ \\
\hline CXCL11/I-TAC & $\begin{array}{l}\text { I-TAC is a chemokine that mediates } \mathrm{T} \text { cell and monocyte chemotaxis. I-TAC is } \\
\text { categorized as an inflammation-related activity. }\end{array}$ \\
\hline CXCL8/IL-8 & $\begin{array}{l}\text { IL-8 is a chemokine that mediates neutrophil recruitment into acute inflammatory sites. } \\
\text { IL-8 is categorized as an inflammation-related activity. }\end{array}$ \\
\hline CXCL9/MIG & $\begin{array}{l}\text { MIG is a chemokine that mediates T cell recruitment. MIG is categorized as an } \\
\text { inflammation-related activity. }\end{array}$ \\
\hline EGFR & $\begin{array}{l}\text { EGFR is a cell surface receptor for epidermal growth factor involved in cell prolifera- } \\
\text { tion during development as well as tumor growth. EGFR is involved in Epithelial cell } \\
\text { proliferation, epithelial cell differentiation keratinocyte proliferation, tissue remodeling. } \\
\text { EGFR is categorized as a tissue remodeling-related activity. }\end{array}$ \\
\hline $\mathrm{M}-\mathrm{CSF}$ & $\begin{array}{l}\text { M-CSF is a secreted and cell surface cytokine that mediates macrophage differentiation. } \\
\text { M-CSF is categorized as an immune modulation-related activity. }\end{array}$ \\
\hline MMP-1 & $\begin{array}{l}\text { MMP-1 is an interstitial collagenase that degrades collagens I, II and III and is involved in the } \\
\text { process of tissue remodeling. MMP-1 is categorized as a tissue remodeling-related activity. }\end{array}$ \\
\hline PAI-I & $\begin{array}{l}\text { PAI-I is a serine proteinase inhibitor and inhibitor of tissue plasminogen activator } \\
\text { (tPA) and urokinase (UPA) and is involved in tissue remodeling and fibrinolysis. } \\
\text { PAI-I is categorized as a tissue remodeling-related activity. }\end{array}$ \\
\hline Proliferation_72hr & $\begin{array}{l}\text { Proliferation_72hr in the HDF3CGF system is a measure of dermal fibroblast } \\
\text { proliferation which is important to the process of wound healing and fibrosis. }\end{array}$ \\
\hline SRB & $\begin{array}{l}\text { SRB is a measure of the total protein content of dermal fibroblasts. Cell viability of ad- } \\
\text { herent cells is measured by Sulforhodamine B (SRB) staining, a method that determines } \\
\text { cell density by measuring total protein content of test wells. }\end{array}$ \\
\hline TIMP-1 & $\begin{array}{l}\text { TIMP-1 is a tissue inhibitor of matrix metalloprotease-7 (MMP-7) and other MMPs, and } \\
\text { is involved in tissue remodeling, angiogenesis and fibrosis. TIMP-1 is categorized as a } \\
\text { tissue remodeling-related activity. }\end{array}$ \\
\hline TIMP-2 & $\begin{array}{l}\text { TIMP-2 is a tissue inhibitor of matrix metalloproteases and is involved in tissue remodeling, } \\
\text { angiogenesis and fibrosis. TIMP-2 is categorized as a tissue remodeling-related activity. }\end{array}$ \\
\hline
\end{tabular}

American Research Journal of Dermatology

Page 3 
The quantitative biomarker data are presented as the mean $\log _{10}$ relative expression level (compared to their respective mean vehicle control value) \pm standard deviation (SD) of triplicate measurements. Differences in biomarker levels between the EOB- and vehicle-treated cultures were tested for significance using the unpaired Student's $t$-test. A p-value $<0.05$, outside of the significance envelope, with an effect size of at least $10 \%\left(>0.05 \log _{10}\right.$ ratio units), was considered statistically significant.

\section{RNA Isolation}

Total RNA was isolated from cell lysates using the ZymoQuick-RNAM in iPrep kit (Zymo Research Corp., Irvine, CA, USA) according to the manufacturer's instructions. RNA concentration was determined using a Nano Drop ND-2000 system (Thermo Fisher Scientific, Waltham, MA, USA). The RNA quality was assessed using a Bioanalyzer 2100 (Agilent Technologies, Santa Clara, CA, USA) and an Agilent RNA 6000 Nano kit. All samples had an A260/A280 ratio between 1.9 and 2.1 and an RNA integrity number score greater than8.0.

\section{Microarray Analysis of Genome-Wide Gene Expression}

The effect of the EOB at a concentration of $0.0033 \%(v / v)$ was tested on the expression of 21,224 genes in the HDF3CGF system following a 24-h treatment. Samples for microarray analysis were processed by Asuragen, Inc. (Austin, TX, USA) according to the company's standard operating procedures. Biotin-labeled cRNAwas prepared from 200 ng total RNA using an Illumina TotalPrep RNA amplification kit (Thermo Fisher Scientific, Waltham, MA, USA) and one round of amplification. The cRNA yields were quantified using ultraviolet spectrophotometry, and the distribution of the transcript sizes was assessed using the Agilent Bioanalyzer 2100. Labeled cRNA (750 ng) was used to probe Illumina human HT-12 v4 expression bead chips (Illumina, Inc., San Diego, CA, USA). Hybridization, washing, staining with streptavidin-conjugated cyanine-3, and scanning of the Illumina arrays were carried out according to the manufacturer's instructions. The Illumina BeadScan software was used to produce the data files for each array, and the raw data were extracted using the Illumina Bead Studio software.

The raw data were uploaded into R (R Development Core Team, 2011), and the quality-control metrics was analyzed using the beadarray package (Dunning et al., 2007). The data were normalized using quantile normalization (Bolstad et al., 2003), and then re-annotated and filtered to remove probes that were non specific or mapped to intronic or intragenic regions (Barbosa-Morais et al., 2010). The remaining probe sets comprised the data set for the subsequent analysis. The fold-change expression for each set was calculated as the log2 ratio of EOB to the vehicle control. These fold-change values were uploaded in to the Ingenuity Pathway Analysis (IPA) program (Qiagen, Redwood City, CA, USA, www.qiagen.com/ingenuity) to generate the networks and pathway analyses.

\section{RESULTS AND DISCUSSION}

\section{Bioactivity Profile of EOB in HDF3CGF System}

The HDF3CGF system was designed to model the pathology of chronic inflammation and wound healing in the context of Th1-type inflammation. Four different concentrations $(0.01,0.0033,0.0011$, and $0.0037 \% \mathrm{v} / \mathrm{v})$ of the EOB were initially tested for cytotoxic activity in the dermal fibroblasts. A concentration of $0.01 \%$ was overtly cytotoxic and, therefore, the $0.0033 \%$ concentration was usedin the further analysis. Biomarkers were designated if the EOB values were significantly different $(\mathrm{p}<0.05)$ from vehicle controls, outside the significance envelope, with an effect size of at least 10\% (>0.05 log ratio units, Figure 1).

Studies by other research groups have shown the anti-inflammatory and immune modulating properties of the major chemical constituents of the EOB, specifically limonene and $\alpha$-pinene. Topically-applied limonene, the main constituent of orange oil, reduced edema in mouse skin and pretreatment with limonene reduced inflammatory markers (Chaudhary et al., 2012). In RAW 264.7 macrophages, limonene reduced several immune markers including TNF- $\alpha$ (Yoon et al., 2010).Limonene's anti-inflammatory effects in rat kidney tissue

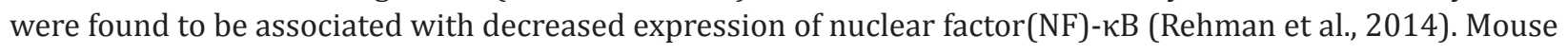


Biological Activity of an Essential Oil Blend in Human Dermal Fibroblasts

studies demonstrated the anti-inflammatory activities of frankincense oil and $\alpha$-pinene, andthe effect was likely mediated by reducingnuclear factor NF- $\mathrm{B}$ nuclear translocation (Zhou et al., 2004). The immunomodulatory effect of $\alpha$-pinene was attributed to the suppression of mitogen-activated protein kinases (MAPKs) and the NF- $\kappa B$ pathway in mouse peritoneal macrophages, which showed decreased expression of TNF- $\alpha$, NF- $\kappa B$, and interleukins (Kim et al., 2015).

The individual essential oils in the EOB that we have studied previously include frankincense and clove oils (Han \& Parker, 2017c, 2017d). It was interesting to observe that certain biomarker effects from the individual essential oils were conserved in the blend, while others were lost. For instance, we previously found that both frankincense and clove oils significantly inhibit cell proliferation, so it was no surprise that the blend also inhibited cell proliferation. Also noteworthy was the MCP-1 downregulation by the blend, which was not observed after treatment with either of the essential oils previously studied. This difference could be attributed to one of the other oils in the blend or perhaps the unique combination of oils. Finally, the blend had virtually no effect on collagen levels, which were significantly downregulated by frankincense andclove oils. These observations support the hypothesis that the EOB has unique biological activity that may perhaps be more than a simple sum of effects from the individual essential oils included in the blend. One obvious limitation to comparing the blend with these oils, however, is our lack of biomarker data on niaouli, litsea, summer savory, thyme, and orange. Future research will make it possible to conduct a more comprehensive comparison of the effects of the EOB compared to its individualcomponent oils.

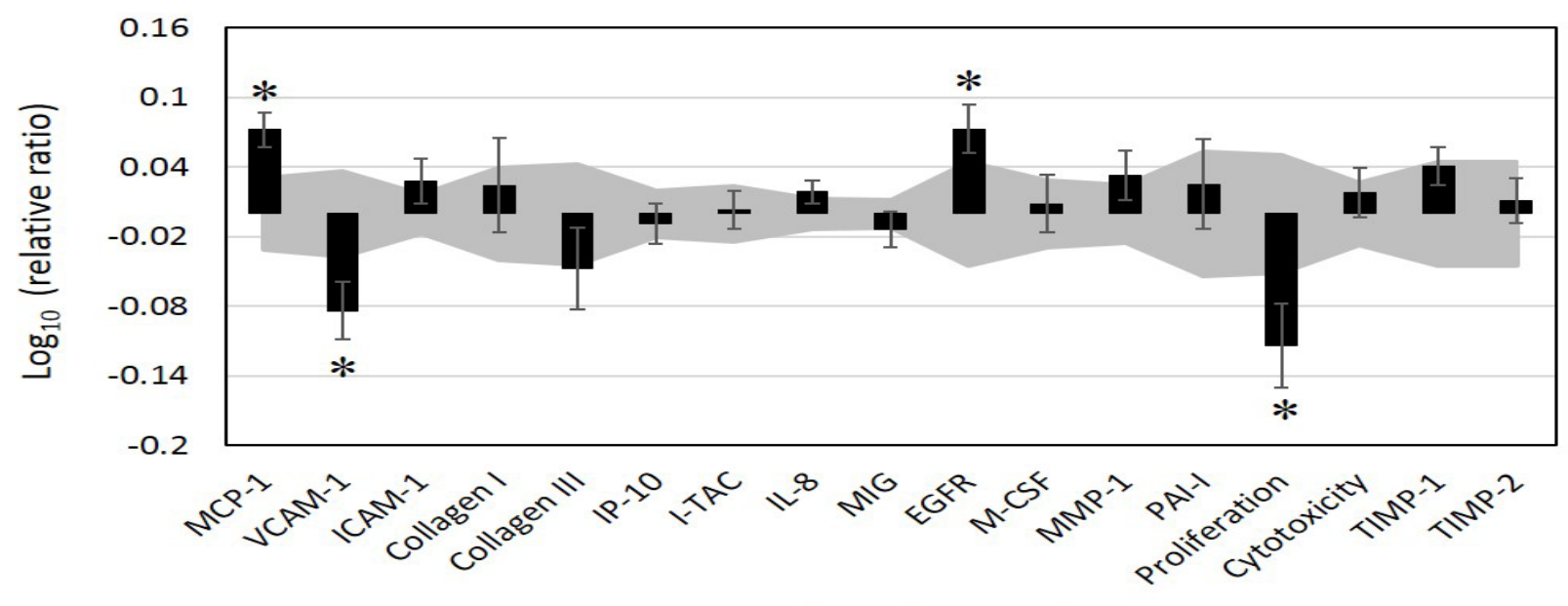

Protein-based Biomarkers

Fig1. The bioactivity profile of an essential oil blend (EOB, $0.0033 \% \mathrm{v} / \mathrm{v})$ in a human dermal fibroblast system HDF3CGF. Y-axis denotes the relative expression levels of biomarkers compared to vehicle control values, in log10 form. Error bars represents the standard deviations (SD) of triplicate measurements. Vehicle control values are shaded in gray, denoting the 95\% significance envelope. A * indicates a biomarker designated with "key activity," i.e., biomarker values were significantly different $(p<0.05)$ from vehicle controls, outside of the significance envelope, with an effect size of at least 10\% (more than 0.05 log ratio units). MCP-1, monocyte chemoattractant protein; VCAM-1, vascular cell adhesion molecule 1; ICAM-1, intracellular cell adhesion molecule 1; IP-10, interferon gamma-induced protein 10; I-TAC, interferon-inducible T-cell alpha chemoattractant; IL-8, interleukin-8; $M I G$, monokine-induced by interferon- $\gamma$; EGFR, epidermal growth factor receptor; M-CSF, macrophage colony-stimulating factor; MMP-1, matrix metalloproteinase 1; PAI-1, plasminogen activator inhibitor 1; TIMP, tissue inhibitor of metalloproteinase

American Research Journal of Dermatology

Page 5 
Biological Activity of an Essential Oil Blend in Human Dermal Fibroblasts

\section{Effect of EOBon Genome-Wide Gene Expression}

To further explore the effect of $0.0033 \%(\mathrm{v} / \mathrm{v}$ ) EOB on human skin cells, we analyzed its effect on the RNA expression of 21, 224 genes. The EOB significantly regulated the expression levels of hundreds of genes globally. The vast majority of the 200mostregulated genes (178) were downregulated by the EOB while the rest were upregulated (Table S2 and see Supplementary Material for more information).

Table S2. 200 most-impacted genes by the EOB (0.0033\% v/v, fold change in log2 ratio form)

\begin{tabular}{|c|c|c|}
\hline Illumina Gene ID & Fold Change & Definition \\
\hline AKR1C4 & 4.38 & $\begin{array}{l}\text { Homo sapiens aldo-keto reductase family 1, member C4 (chlordecone } \\
\text { reductase; 3-alpha hydroxysteroid dehydrogenase, type I; dihydrodiol } \\
\text { dehydrogenase 4) (AKR } 1 \text { C4), mRNA. }\end{array}$ \\
\hline MMP10 & 4.13 & $\begin{array}{l}\text { Homo sapiens matrix metallopeptidase } 10 \text { (stromelysin 2) (MMP10), } \\
\text { mRNA. }\end{array}$ \\
\hline RSAD2 & 3.87 & $\begin{array}{l}\text { Homo sapiens radical S-adenosyl methionine domain containing } 2 \\
\text { (RSAD2), mRNA. }\end{array}$ \\
\hline AKR1C2 & 3.66 & $\begin{array}{l}\text { Homo sapiens aldo-keto reductase family 1, member C2 (dihydrodiol } \\
\text { dehydrogenase 2; bile acid binding protein; 3-alpha hydroxysteroid } \\
\text { dehydrogenase,type III) (AKR1C2), transcript variant1, mRNA.XM_943424 } \\
\text { XM_943425 XM_943427 }\end{array}$ \\
\hline SLC7A11 & 3.17 & $\begin{array}{l}\text { Homo sapiens solute carrier family 7, (cationic amino acid transporter, y+ } \\
\text { system) member } 11 \text { (SLC7A11), mRNA. }\end{array}$ \\
\hline ODC1 & 2.69 & Homo sapiens ornithine decarboxylase 1 (ODC1), mRNA. \\
\hline TFRC & 2.64 & Homo sapiens transferrin receptor (p90, CD71) (TFRC), mRNA. \\
\hline GLDN & 2.57 & Homo sapiens gliomedin (GLDN), mRNA. \\
\hline TDO2 & 2.47 & Homo sapiens tryptophan 2,3-dioxygenase (TDO2), mRNA. \\
\hline TELO2 & 2.39 & $\begin{array}{l}\text { Homo sapiens TEL2, telomere maintenance 2, homolog (S. cerevisiae) } \\
\text { (TELO2), mRNA. }\end{array}$ \\
\hline ANGPTL4 & 2.27 & Homo sapiens angiopoietin-like 4 (ANGPTL4), transcript variant 1, mRNA. \\
\hline MAP2 & 2.21 & $\begin{array}{l}\text { Homo sapiens microtubule-associated protein } 2 \text { (MAP2), transcript variant } \\
\text { 1, mRNA. }\end{array}$ \\
\hline GPR1 & 2.13 & $\begin{array}{l}\text { Homo sapiens G protein-coupled receptor } 1 \text { (GPR1), transcript variant 2, } \\
\text { mRNA. }\end{array}$ \\
\hline FAM167A & 2.13 & $\begin{array}{l}\text { Homo sapiens family with sequence similarity } 167 \text {, member A (FAM167A), } \\
\text { mRNA. }\end{array}$ \\
\hline RPS7 & 2.13 & Homo sapiens ribosomal protein S7 (RPS7), mRNA. \\
\hline TSPAN13 & 2.13 & Homo sapiens tetraspanin 13 (TSPAN13), mRNA. \\
\hline SYT7 & 2.12 & Homo sapiens synaptotagmin VII (SYT7), mRNA. \\
\hline ECE2 & 2.11 & $\begin{array}{l}\text { Homo sapiens endothelin converting enzyme } 2 \text { (ECE2), transcript variant } \\
\text { 3, mRNA. }\end{array}$ \\
\hline C80RF13 & 2.07 & Homo sapiens chromosome 8 open reading frame 13 (C8orf13), mRNA. \\
\hline RPS7 & 2.06 & Homo sapiens ribosomal protein S7 (RPS7), mRNA. \\
\hline DHRS7 & 2.05 & $\begin{array}{l}\text { Homo sapiens dehydrogenase/reductase (SDR family) member } 7 \text { (DHRS7), } \\
\text { mRNA. }\end{array}$ \\
\hline
\end{tabular}


Biological Activity of an Essential Oil Blend in Human Dermal Fibroblasts

\begin{tabular}{|c|c|c|}
\hline ST6GALNAC3 & 2.05 & $\begin{array}{l}\text { Homo sapiens ST6 (alpha-N-acetyl-neuraminyl-2,3-beta-galactosyl-1,3)- } \\
\text { N-acetylgalactosaminide alpha-2, 6-sialyltransferase } 3 \text { (ST6GALNAC3), } \\
\text { mRNA. }\end{array}$ \\
\hline DIAPH3 & -2.05 & $\begin{array}{l}\text { Homo sapiens diaphanous homolog } 3 \text { (Drosophila) (DIAPH3), transcript } \\
\text { variant } 1 \text {, mRNA. }\end{array}$ \\
\hline LOC649143 & -2.05 & $\begin{array}{l}\text { PREDICTED: Homo sapiens similar to HLA class II histocompatibility } \\
\text { antigen, DRB1-9 beta chain precursor (MHC class I antigen DRB1*9) (DR-9) } \\
\text { (DR9), transcript variant } 2 \text { (LOC649143), mRNA. }\end{array}$ \\
\hline FOXM1 & -2.06 & Homo sapiens forkhead box M1 (FOXM1), transcript variant 2, mRNA. \\
\hline CCL3L3 & -2.06 & Homo sapiens chemokine (C-C motif) ligand 3-like 3 (CCL3L3), mRNA. \\
\hline ELF3 & -2.06 & $\begin{array}{l}\text { Homo sapiens E74-like factor } 3 \text { (ets domain transcription factor, epithelial- } \\
\text { specific ) (ELF3), mRNA. }\end{array}$ \\
\hline ADD3 & -2.06 & Homo sapiens adducin 3 (gamma) (ADD3), transcript variant 3, mRNA. \\
\hline HLA-DRB6 & -2.06 & $\begin{array}{l}\text { Homo sapiens major histocompatibility complex, class II, DR beta } 6 \\
\text { (pseudogene) (HLA-DRB6), non-coding RNA. }\end{array}$ \\
\hline CKAP2L & -2.07 & Homo sapiens cytoskeleton associated protein 2-like (CKAP2L), mRNA. \\
\hline CALD1 & -2.07 & Homo sapiens caldesmon 1 (CALD1), transcript variant 5, mRNA. \\
\hline FLJ21986 & -2.07 & Homo sapiens hypothetical protein FLJ21986 (FLJ21986), mRNA. \\
\hline ADD3 & -2.07 & Homo sapiens adducin 3 (gamma) (ADD3), transcript variant 3, mRNA. \\
\hline NNMT & -2.08 & Homo sapiens nicotinamide N-methyltransferase (NNMT), mRNA. \\
\hline ENPEP & -2.08 & $\begin{array}{l}\text { Homo sapiens glutamyl aminopeptidase (aminopeptidase A) (ENPEP), } \\
\text { mRNA. }\end{array}$ \\
\hline NUF2 & -2.09 & $\begin{array}{l}\text { Homo sapiens NUF2, NDC80 kinetochore complex component, homolog (S. } \\
\text { cerevisiae) (NUF2), transcript variant } 2 \text {, mRNA. }\end{array}$ \\
\hline LYPD1 & -2.09 & $\begin{array}{l}\text { Homo sapiens LY6/PLAUR domain containing } 1 \text { (LYPD1), transcript variant } \\
\text { 1, mRNA. }\end{array}$ \\
\hline CCNA2 & -2.09 & Homo sapiens cyclin A2 (CCNA2), mRNA. \\
\hline ANKRD22 & -2.09 & Homo sapiens ankyrin repeat domain 22 (ANKRD22), mRNA. \\
\hline P4HA2 & -2.09 & $\begin{array}{l}\text { Homo sapiens prolyl 4-hydroxylase, alpha polypeptide II (P4HA2), } \\
\text { transcript variant 2, mRNA. }\end{array}$ \\
\hline COL4A2 & -2.10 & Homo sapiens collagen, type IV, alpha 2 (COL4A2), mRNA. \\
\hline C100RF58 & -2.10 & $\begin{array}{l}\text { Homo sapiens chromosome } 10 \text { open reading frame } 58 \text { (C10orf58), } \\
\text { transcript variant } 1 \text {, mRNA. }\end{array}$ \\
\hline DIAPH3 & -2.11 & $\begin{array}{l}\text { Homo sapiens diaphanous homolog } 3 \text { (Drosophila) (DIAPH3), transcript } \\
\text { variant } 1 \text {, mRNA. }\end{array}$ \\
\hline CHN1 & -2.11 & $\begin{array}{l}\text { Homo sapiens chimerin (chimaerin) } 1 \text { (CHN1), transcript variant } 2 \text {, } \\
\text { mRNA. }\end{array}$ \\
\hline FANCI & -2.11 & $\begin{array}{l}\text { Homo sapiens Fanconi anemia, complementation group I (FANCI), } \\
\text { transcript variant 2, mRNA. }\end{array}$ \\
\hline HJURP & -2.11 & Homo sapiens Holliday junction recognition protein (HJURP), mRNA. \\
\hline ACSL5 & -2.11 & $\begin{array}{l}\text { Homo sapiens acyl-CoA synthetase long-chain family member } 5 \text { (ACSL5), } \\
\text { transcript variant 2, mRNA. }\end{array}$ \\
\hline
\end{tabular}


Biological Activity of an Essential Oil Blend in Human Dermal Fibroblasts

\begin{tabular}{|c|c|c|}
\hline HLA-DRB5 & -2.12 & $\begin{array}{l}\text { Homo sapiens major histocompatibility complex, class II, DR beta } 5 \\
\text { (HLA-DRB5), mRNA. }\end{array}$ \\
\hline BNIP3L & -2.12 & $\begin{array}{l}\text { Homo sapiens BCL2/adenovirus E1B } 19 \mathrm{kDa} \text { interacting protein 3-like } \\
\text { (BNIP3L), mRNA. }\end{array}$ \\
\hline LIMK2 & -2.12 & Homo sapiens LIM domain kinase 2 (LIMK2), transcript variant 1, mRNA. \\
\hline FBX032 & -2.13 & Homo sapiens F-box protein 32 (FBX032), transcript variant 2, mRNA. \\
\hline CCL11 & -2.14 & Homo sapiens chemokine (C-C motif) ligand 11 (CCL11), mRNA. \\
\hline TMEM45A & -2.15 & Homo sapiens transmembrane protein 45A (TMEM45A), mRNA. \\
\hline XIRP1 & -2.17 & Homo sapiens xin actin-binding repeat containing 1 (XIRP1), mRNA. \\
\hline KIF23 & -2.17 & $\begin{array}{l}\text { Homo sapiens kinesin family member } 23 \text { (KIF23), transcript variant 2, } \\
\text { mRNA. }\end{array}$ \\
\hline MAP1LC3A & -2.17 & $\begin{array}{l}\text { Homo sapiens microtubule-associated protein } 1 \text { light chain } 3 \text { alpha } \\
\text { (MAP1LC3A), transcript variant } 2 \text {, mRNA. }\end{array}$ \\
\hline ENO2 & -2.18 & Homo sapiens enolase 2 (gamma, neuronal) (ENO2), mRNA. \\
\hline FRMD4A & -2.18 & Homo sapiens FERM domain containing 4A (FRMD4A), mRNA. \\
\hline CXCL6 & -2.19 & $\begin{array}{l}\text { Homo sapiens chemokine (C-X-C motif) ligand } 6 \text { (granulocyte chemotactic } \\
\text { protein 2) (CXCL6), mRNA. }\end{array}$ \\
\hline ABCA6 & -2.19 & $\begin{array}{l}\text { Homo sapiens ATP-binding cassette, sub-family A (ABC1), member } 6 \\
\text { (ABCA6), mRNA. }\end{array}$ \\
\hline C60RF173 & -2.19 & Homo sapiens chromosome 6 open reading frame 173 (C6orf173), mRNA. \\
\hline ARHGEF3 & -2.20 & $\begin{array}{l}\text { Homo sapiens Rho guanine nucleotide exchange factor (GEF) } 3 \text { (ARHGEF3), } \\
\text { mRNA. }\end{array}$ \\
\hline FABP3 & -2.20 & $\begin{array}{l}\text { Homo sapiens fatty acid binding protein 3, muscle and heart } \\
\text { (mammary-derived growth inhibitor) (FABP3), mRNA. }\end{array}$ \\
\hline AQP9 & -2.20 & Homo sapiens aquaporin 9 (AQP9), mRNA. \\
\hline TEX11 & -2.20 & Homo sapiens testis expressed 11 (TEX11), transcript variant 1, mRNA. \\
\hline CDC45L & -2.20 & $\begin{array}{l}\text { Homo sapiens CDC } 45 \text { cell division cycle } 45 \text {-like (S. cerevisiae) (CDC45L), } \\
\text { mRNA. }\end{array}$ \\
\hline IGFBP5 & -2.22 & $\begin{array}{l}\text { Homo sapiens insulin-like growth factor binding protein } 5 \text { (IGFBP5), } \\
\text { mRNA. }\end{array}$ \\
\hline NHS & -2.22 & $\begin{array}{l}\text { Homo sapiens Nance-Horan syndrome (congenital cataracts and dental } \\
\text { anomalies) (NHS), transcript variant } 1, \text { mRNA. }\end{array}$ \\
\hline ACSL5 & -2.22 & $\begin{array}{l}\text { Homo sapiens acyl-CoA synthetase long-chain family member } 5 \text { (ACSL5), } \\
\text { transcript variant } 1 \text {, mRNA. }\end{array}$ \\
\hline NDP & -2.22 & Homo sapiens Norrie disease (pseudoglioma) (NDP), mRNA. \\
\hline LOC100133923 & -2.22 & $\begin{array}{l}\text { PREDICTED: Homo sapiens hypothetical protein LOC100133923 } \\
\text { (LOC100133923), mRNA. }\end{array}$ \\
\hline KIF2C & -2.23 & Homo sapiens kinesin family member 2C (KIF2C), mRNA. \\
\hline RARRES1 & -2.23 & $\begin{array}{l}\text { Homo sapiens retinoic acid receptor responder (tazarotene induced) } 1 \\
\text { (RARRES1), transcript variant } 1, \text { mRNA. }\end{array}$ \\
\hline MYLK & -2.23 & $\begin{array}{l}\text { Homo sapiens myosin light chain kinase (MYLK), transcript variant } 8 \text {, } \\
\text { mRNA. }\end{array}$ \\
\hline
\end{tabular}


Biological Activity of an Essential Oil Blend in Human Dermal Fibroblasts

\begin{tabular}{|c|c|c|}
\hline SIRPA & -2.24 & $\begin{array}{l}\text { Homo sapiens signal-regulatory protein alpha (SIRPA), transcript variant } \\
\text { 3, mRNA. }\end{array}$ \\
\hline ROR2 & -2.24 & $\begin{array}{l}\text { Homo sapiens receptor tyrosine kinase-like orphan receptor } 2 \text { (ROR2), } \\
\text { mRNA. }\end{array}$ \\
\hline PIM1 & -2.26 & Homo sapiens pim-1 oncogene (PIM1), mRNA. \\
\hline KIF11 & -2.26 & Homo sapiens kinesin family member 11 (KIF11), mRNA. \\
\hline GRAMD3 & -2.26 & Homo sapiens GRAM domain containing 3 (GRAMD3), mRNA. \\
\hline ZWINT & -2.26 & Homo sapiens ZW10 interactor (ZWINT), transcript variant 3, mRNA. \\
\hline INSIG2 & -2.26 & Homo sapiens insulin induced gene 2 (INSIG2), mRNA. \\
\hline NUSAP1 & -2.27 & $\begin{array}{l}\text { Homo sapiens nucleolar and spindle associated protein } 1 \text { (NUSAP1), } \\
\text { transcript variant } 2 \text {, mRNA. }\end{array}$ \\
\hline PIK3IP1 & -2.27 & $\begin{array}{l}\text { Homo sapiens phosphoinositide-3-kinase interacting protein } 1 \text { (PIK3IP1), } \\
\text { mRNA. }\end{array}$ \\
\hline CDCA5 & -2.27 & Homo sapiens cell division cycle associated 5 (CDCA5), mRNA. \\
\hline NCCRP1 & -2.29 & $\begin{array}{l}\text { Homo sapiens non-specific cytotoxic cell receptor protein } 1 \text { homolog } \\
\text { (zebrafish) (NCCRP1), mRNA. }\end{array}$ \\
\hline PLAT & -2.29 & Homo sapiens plasminogen activator, tissue (PLAT), transcript variant 1, mRNA. \\
\hline CXCL9 & -2.29 & Homo sapiens chemokine (C-X-C motif) ligand 9 (CXCL9), mRNA. \\
\hline HNMT & -2.30 & $\begin{array}{l}\text { Homo sapiens histamine N-methyltransferase (HNMT), transcript variant } \\
\text { 2, mRNA. }\end{array}$ \\
\hline LOC100131093 & -2.30 & PREDICTED: Homo sapiens misc_RNA (LOC100131093), miscRNA. \\
\hline TACC3 & -2.30 & $\begin{array}{l}\text { Homo sapiens transforming, acidic coiled-coil containing protein } 3 \\
\text { (TACC3), mRNA. }\end{array}$ \\
\hline DLGAP5 & -2.32 & $\begin{array}{l}\text { Homo sapiens discs, large (Drosophila) homolog-associated protein } 5 \\
\text { (DLGAP5), mRNA. }\end{array}$ \\
\hline JAM2 & -2.32 & Homo sapiens junctional adhesion molecule 2 (JAM2), mRNA. \\
\hline TPX2 & -2.33 & $\begin{array}{l}\text { Homo sapiens TPX2, microtubule-associated, homolog (Xenopus laevis) } \\
\text { (TPX2), mRNA. }\end{array}$ \\
\hline PSTPIP2 & -2.34 & $\begin{array}{l}\text { Homo sapiens proline-serine-threonine phosphatase interacting protein } 2 \\
\text { (PSTPIP2), mRNA. }\end{array}$ \\
\hline ASF1B & -2.36 & $\begin{array}{l}\text { Homo sapiens ASF1 anti-silencing function } 1 \text { homolog B (S. cerevisiae) } \\
\text { (ASF1B), mRNA. }\end{array}$ \\
\hline HECW2 & -2.37 & $\begin{array}{l}\text { Homo sapiens HECT, C2 and WW domain containing E3 ubiquitin protein } \\
\text { ligase } 2 \text { (HECW2), mRNA. }\end{array}$ \\
\hline CLDN7 & -2.37 & Homo sapiens claudin 7 (CLDN7), mRNA. \\
\hline G0S2 & -2.38 & Homo sapiens G0/G1switch 2 (G0S2), mRNA. \\
\hline CEACAM1 & -2.38 & $\begin{array}{l}\text { Homo sapiens carcinoembryonic antigen-related cell adhesion molecule } 1 \\
\text { (biliary glycoprotein) (CEACAM1), transcript variant } 2 \text {, mRNA. }\end{array}$ \\
\hline HMMR & -2.39 & $\begin{array}{l}\text { Homo sapiens hyaluronan-mediated motility receptor (RHAMM) (HMMR), } \\
\text { transcript variant 2, mRNA. }\end{array}$ \\
\hline FAM20A & -2.39 & $\begin{array}{l}\text { Homo sapiens family with sequence similarity 20, member A (FAM20A), } \\
\text { mRNA. }\end{array}$ \\
\hline
\end{tabular}


Biological Activity of an Essential Oil Blend in Human Dermal Fibroblasts

\begin{tabular}{|c|c|c|}
\hline CCNB2 & -2.40 & Homo sapiens cyclin B2 (CCNB2), mRNA. \\
\hline HLA-F & -2.40 & $\begin{array}{l}\text { Homo sapiens major histocompatibility complex, class I, F (HLA-F), } \\
\text { transcript variant } 1 \text {, mRNA. }\end{array}$ \\
\hline NOD2 & -2.40 & $\begin{array}{l}\text { Homo sapiens nucleotide-binding oligomerization domain containing } 2 \\
\text { (NOD2), mRNA. }\end{array}$ \\
\hline RARRES3 & -2.44 & $\begin{array}{l}\text { Homo sapiens retinoic acid receptor responder (tazarotene induced) } 3 \\
\text { (RARRES3), mRNA. }\end{array}$ \\
\hline STEAP4 & -2.46 & Homo sapiens STEAP family member 4 (STEAP4), mRNA. \\
\hline ASCL2 & -2.47 & $\begin{array}{l}\text { Homo sapiens achaete-scute complex homolog } 2 \text { (Drosophila) (ASCL2), } \\
\text { mRNA. }\end{array}$ \\
\hline AK3L1 & -2.50 & $\begin{array}{l}\text { Homo sapiens adenylate kinase } 3 \text {-like } 1 \text { (AK3L1), nuclear gene encoding } \\
\text { mitochondrial protein, transcript variant } 7 \text {, mRNA. }\end{array}$ \\
\hline MT3 & -2.51 & Homo sapiens metallothionein 3 (MT3), mRNA. \\
\hline ACAT2 & -2.51 & Homo sapiens acetyl-Coenzyme A acetyltransferase 2 (ACAT2), mRNA. \\
\hline CEP55 & -2.51 & Homo sapiens centrosomal protein 55kDa (CEP55), mRNA. \\
\hline ASPM & -2.52 & $\begin{array}{l}\text { Homo sapiens asp (abnormal spindle) homolog, microcephaly associated } \\
\text { (Drosophila) (ASPM), mRNA. }\end{array}$ \\
\hline AK3L1 & -2.52 & $\begin{array}{l}\text { Homo sapiens adenylate kinase } 3 \text {-like } 1 \text { (AK3L1), nuclear gene encoding } \\
\text { mitochondrial protein, transcript variant } 6 \text {, mRNA. }\end{array}$ \\
\hline CARHSP1 & -2.53 & $\begin{array}{l}\text { Homo sapiens calcium regulated heat stable protein } 1,24 \mathrm{kDa} \text { (CARHSP1), } \\
\text { transcript variant } 2 \text {, mRNA. }\end{array}$ \\
\hline MT1F & -2.53 & Homo sapiens metallothionein 1F (MT1F), mRNA. \\
\hline CDC2 & -2.55 & $\begin{array}{l}\text { Homo sapiens cell division cycle } 2, \mathrm{G} 1 \text { to } \mathrm{S} \text { and } \mathrm{G} 2 \text { to } \mathrm{M} \text { (CDC2), transcript } \\
\text { variant } 1 \text {, mRNA. }\end{array}$ \\
\hline IL1A & -2.55 & Homo sapiens interleukin 1, alpha (IL1A), mRNA. \\
\hline IL4I1 & -2.57 & $\begin{array}{l}\text { Homo sapiens interleukin } 4 \text { induced } 1 \text { (IL4I1), transcript variant 2, } \\
\text { mRNA. }\end{array}$ \\
\hline TYMS & -2.57 & Homo sapiens thymidylate synthetase (TYMS), mRNA. \\
\hline CDKN3 & -2.58 & $\begin{array}{l}\text { Homo sapiens cyclin-dependent kinase inhibitor } 3 \text { (CDK2-associated dual } \\
\text { specificity phosphatase) (CDKN3), mRNA. }\end{array}$ \\
\hline KIF4A & -2.59 & Homo sapiens kinesin family member 4A (KIF4A), mRNA. \\
\hline CDCA3 & -2.59 & Homo sapiens cell division cycle associated 3 (CDCA3), mRNA. \\
\hline ALDOC & -2.59 & Homo sapiens aldolase C, fructose-bisphosphate (ALDOC), mRNA. \\
\hline ADAMDEC1 & -2.59 & Homo sapiens ADAM-like, decysin 1 (ADAMDEC1), mRNA. \\
\hline KIFC1 & -2.62 & Homo sapiens kinesin family member C1 (KIFC1), mRNA. \\
\hline CD38 & -2.63 & Homo sapiens CD38 molecule (CD38), mRNA. \\
\hline NDC80 & -2.64 & $\begin{array}{l}\text { Homo sapiens NDC80 homolog, kinetochore complex component (S. } \\
\text { cerevisiae) (NDC80), mRNA. }\end{array}$ \\
\hline
\end{tabular}


Biological Activity of an Essential Oil Blend in Human Dermal Fibroblasts

\begin{tabular}{|c|c|c|}
\hline MELK & -2.64 & Homo sapiens maternal embryonic leucine zipper kinase (MELK), mRNA. \\
\hline HLA-DRB6 & -2.64 & $\begin{array}{l}\text { Homo sapiens major histocompatibility complex, class II, DR beta } 6 \\
\text { (pseudogene) (HLA-DRB6), non-coding RNA. }\end{array}$ \\
\hline MMP9 & -2.65 & $\begin{array}{l}\text { Homo sapiens matrix metallopeptidase } 9 \text { (gelatinase B, } 92 \mathrm{kDa} \text { gelatinase, } \\
\text { 92kDa type IV collagenase) (MMP9), mRNA. }\end{array}$ \\
\hline TP53INP2 & -2.66 & $\begin{array}{l}\text { Homo sapiens tumor protein p53 inducible nuclear protein } 2 \text { (TP53INP2), } \\
\text { mRNA. }\end{array}$ \\
\hline BIRC5 & -2.66 & $\begin{array}{l}\text { Homo sapiens baculoviral IAP repeat-containing } 5 \text { (BIRC5), transcript } \\
\text { variant } 1 \text {, mRNA. }\end{array}$ \\
\hline SHRM & -2.70 & Homo sapiens shroom (SHRM), mRNA. \\
\hline HLA-DRB1 & -2.70 & $\begin{array}{l}\text { Homo sapiens major histocompatibility complex, class II, DR beta } 1 \\
\text { (HLA-DRB1), mRNA. }\end{array}$ \\
\hline RRM2 & -2.70 & Homo sapiens ribonucleotide reductase M2 polypeptide (RRM2), mRNA. \\
\hline SRGN & -2.74 & Homo sapiens serglycin (SRGN), mRNA. \\
\hline MT1JP & -2.75 & Homo sapiens metallothionein 1J (pseudogene) (MT1JP), mRNA. \\
\hline AK3L1 & -2.76 & $\begin{array}{l}\text { Homo sapiens adenylate kinase } 3 \text {-like } 1 \text { (AK3L1), nuclear gene encoding } \\
\text { mitochondrial protein, transcript variant } 7 \text {, mRNA. }\end{array}$ \\
\hline SLC39A8 & -2.77 & $\begin{array}{l}\text { Homo sapiens solute carrier family } 39 \text { (zinc transporter), member } 8 \\
\text { (SLC39A8), transcript variant } 1 \text {, mRNA. }\end{array}$ \\
\hline RARRES1 & -2.77 & $\begin{array}{l}\text { Homo sapiens retinoic acid receptor responder (tazarotene induced) } 1 \\
\text { (RARRES1), transcript variant } 2, \text { mRNA. }\end{array}$ \\
\hline TK1 & -2.79 & Homo sapiens thymidine kinase 1 , soluble (TK1), mRNA. \\
\hline PBK & -2.79 & Homo sapiens PDZ binding kinase (PBK), mRNA. \\
\hline JUP & -2.81 & Homo sapiens junction plakoglobin (JUP), transcript variant 1, mRNA. \\
\hline APOBEC3B & -2.84 & $\begin{array}{l}\text { Homo sapiens apolipoprotein B mRNA editing enzyme, catalytic } \\
\text { polypeptide-like } 3 \mathrm{~B} \text { (APOBEC3B), mRNA. }\end{array}$ \\
\hline HMMR & -2.85 & $\begin{array}{l}\text { Homo sapiens hyaluronan-mediated motility receptor (RHAMM) (HMMR), } \\
\text { transcript variant } 1 \text {, mRNA. }\end{array}$ \\
\hline DLGAP5 & -2.91 & $\begin{array}{l}\text { Homo sapiens discs, large (Drosophila) homolog-associated protein } 5 \\
\text { (DLGAP5), mRNA. }\end{array}$ \\
\hline SCARA3 & -2.93 & $\begin{array}{l}\text { Homo sapiens scavenger receptor class A, member } 3 \text { (SCARA3), transcript } \\
\text { variant } 1 \text {, mRNA. }\end{array}$ \\
\hline C90RF135 & -2.96 & Homo sapiens chromosome 9 open reading frame 135 (C9orf135), mRNA. \\
\hline CYB5A & -2.97 & $\begin{array}{l}\text { Homo sapiens cytochrome b5 type A (microsomal) (CYB5A), transcript } \\
\text { variant } 2 \text {, mRNA. }\end{array}$ \\
\hline RASD1 & -2.98 & Homo sapiens RAS, dexamethasone-induced 1 (RASD1), mRNA. \\
\hline ANLN & -2.98 & Homo sapiens anillin, actin binding protein (ANLN), mRNA. \\
\hline KIF11 & -2.99 & Homo sapiens kinesin family member 11 (KIF11), mRNA. \\
\hline
\end{tabular}


Biological Activity of an Essential Oil Blend in Human Dermal Fibroblasts

\begin{tabular}{|c|c|c|}
\hline SCARA3 & -3.02 & $\begin{array}{l}\text { Homo sapiens scavenger receptor class A, member } 3 \text { (SCARA3), transcript } \\
\text { variant } 2 \text {, mRNA. }\end{array}$ \\
\hline IL32 & -3.03 & Homo sapiens interleukin 32 (IL32), transcript variant 4, mRNA. \\
\hline HLA-DPA1 & -3.04 & $\begin{array}{l}\text { Homo sapiens major histocompatibility complex, class II, DP alpha } \\
1 \text { (HLA-DPA1), mRNA. }\end{array}$ \\
\hline KIAA0101 & -3.05 & Homo sapiens KIAA0101 (KIAA0101), transcript variant 1, mRNA. \\
\hline CDC2 & -3.07 & $\begin{array}{l}\text { Homo sapiens cell division cycle } 2, \mathrm{G} 1 \text { to } \mathrm{S} \text { and } \mathrm{G} 2 \text { to } \mathrm{M} \text { (CDC2), transcript } \\
\text { variant } 1, \text { mRNA. }\end{array}$ \\
\hline TNFSF10 & -3.16 & $\begin{array}{l}\text { Homo sapiens tumor necrosis factor (ligand) superfamily, member } 10 \\
\text { (TNFSF10), mRNA. }\end{array}$ \\
\hline SRGN & -3.21 & Homo sapiens serglycin (SRGN), mRNA. \\
\hline SEPT4 & -3.21 & Homo sapiens septin 4 (SEPT4), transcript variant 1, mRNA. \\
\hline MT1H & -3.22 & Homo sapiens metallothionein 1H (MT1H), mRNA. \\
\hline MUC1 & -3.28 & $\begin{array}{l}\text { Homo sapiens mucin } 1 \text {, cell surface associated (MUC1), transcript variant } \\
6 \text {, mRNA. }\end{array}$ \\
\hline SEPT4 & -3.29 & Homo sapiens septin 4 (SEPT4), transcript variant 3, mRNA. \\
\hline HS.10862 & -3.32 & Homo sapiens cDNA: FLJ23313 fis, clone HEP11919 \\
\hline SLC26A4 & -3.33 & Homo sapiens solute carrier family 26, member 4 (SLC26A4), mRNA. \\
\hline SLC39A8 & -3.35 & $\begin{array}{l}\text { Homo sapiens solute carrier family } 39 \text { (zinc transporter), member } 8 \\
\text { (SLC39A8), transcript variant } 1 \text {, mRNA. }\end{array}$ \\
\hline IGFBP7 & -3.35 & $\begin{array}{l}\text { Homo sapiens insulin-like growth factor binding protein } 7 \text { (IGFBP7), } \\
\text { mRNA. }\end{array}$ \\
\hline AURKB & -3.37 & Homo sapiens aurora kinase B (AURKB), mRNA. \\
\hline HLA-DRB4 & -3.37 & $\begin{array}{l}\text { Homo sapiens major histocompatibility complex, class II, DR beta } 4 \\
\text { (HLA-DRB4), mRNA. }\end{array}$ \\
\hline NUSAP1 & -3.38 & $\begin{array}{l}\text { Homo sapiens nucleolar and spindle associated protein } 1 \text { (NUSAP1), } \\
\text { transcript variant } 2 \text {, mRNA. }\end{array}$ \\
\hline SAA1 & -3.39 & Homo sapiens serum amyloid A1 (SAA1), transcript variant 2, mRNA. \\
\hline NCAPG & -3.47 & Homo sapiens non-SMC condensin I complex, subunit G (NCAPG), mRNA. \\
\hline UBE2C & -3.54 & $\begin{array}{l}\text { Homo sapiens ubiquitin-conjugating enzyme E2C (UBE2C), transcript } \\
\text { variant } 3 \text {, mRNA. }\end{array}$ \\
\hline CYB5A & -3.55 & $\begin{array}{l}\text { Homo sapiens cytochrome b5 type A (microsomal) (CYB5A), transcript } \\
\text { variant } 2 \text {, mRNA. }\end{array}$ \\
\hline HLA-DRA & -3.58 & $\begin{array}{l}\text { Homo sapiens major histocompatibility complex, class II, DR alpha } \\
\text { (HLA-DRA), mRNA. }\end{array}$ \\
\hline UBE2C & -3.60 & $\begin{array}{l}\text { Homo sapiens ubiquitin-conjugating enzyme E2C (UBE2C), transcript } \\
\text { variant } 6, \text { mRNA. }\end{array}$ \\
\hline HIST1H4C & -3.63 & Homo sapiens histone cluster 1, H4c (HIST1H4C), mRNA. \\
\hline
\end{tabular}


Biological Activity of an Essential Oil Blend in Human Dermal Fibroblasts

\begin{tabular}{|c|c|c|}
\hline PRC1 & -3.66 & $\begin{array}{l}\text { Homo sapiens protein regulator of cytokinesis } 1 \text { (PRC1), transcript variant } \\
2 \text {, mRNA. }\end{array}$ \\
\hline TOP2A & -3.71 & Homo sapiens topoisomerase (DNA) II alpha $170 \mathrm{kDa}$ (TOP2A), mRNA. \\
\hline PALLD & -3.94 & $\begin{array}{l}\text { Homo sapiens palladin, cytoskeletal associated protein (PALLD), transcript } \\
\text { variant } 2 \text {, mRNA. }\end{array}$ \\
\hline HAS3 & -3.96 & Homo sapiens hyaluronan synthase 3 (HAS3), transcript variant 1, mRNA. \\
\hline VCAM1 & -4.27 & $\begin{array}{l}\text { Homo sapiens vascular cell adhesion molecule } 1 \text { (VCAM1), transcript } \\
\text { variant } 1 \text {, mRNA. }\end{array}$ \\
\hline LOC730415 & -4.42 & $\begin{array}{l}\text { PREDICTED: Homo sapiens hypothetical LOC730415, transcript variant } 2 \\
\text { (LOC730415), mRNA. }\end{array}$ \\
\hline VCAM1 & -4.67 & $\begin{array}{l}\text { Homo sapiens vascular cell adhesion molecule } 1 \text { (VCAM1), transcript } \\
\text { variant } 1 \text {, mRNA. }\end{array}$ \\
\hline HLA-DRA & -4.70 & $\begin{array}{l}\text { Homo sapiens major histocompatibility complex, class II, DR alpha (HLA- } \\
\text { DRA), mRNA. }\end{array}$ \\
\hline METTL7A & -4.71 & Homo sapiens methyltransferase like 7A (METTL7A), mRNA. \\
\hline CFB & -4.83 & Homo sapiens complement factor B (CFB), mRNA. \\
\hline CX3CL1 & -5.09 & Homo sapiens chemokine (C-X3-C motif) ligand 1 (CX3CL1), mRNA. \\
\hline SEPT4 & -5.21 & Homo sapiens septin 4 (SEPT4), transcript variant 2, mRNA. \\
\hline LIPG & -5.24 & Homo sapiens lipase, endothelial (LIPG), mRNA. \\
\hline UBD & -5.80 & Homo sapiens ubiquitin D (UBD), mRNA. \\
\hline HSD11B1 & -5.88 & $\begin{array}{l}\text { Homo sapiens hydroxysteroid (11-beta) dehydrogenase } 1 \text { (HSD11B1), } \\
\text { transcript variant } 2 \text {, mRNA. }\end{array}$ \\
\hline CD74 & -6.12 & $\begin{array}{l}\text { Homo sapiens CD74 molecule, major histocompatibility complex, class II } \\
\text { invariant chain (CD74), transcript variant } 2 \text {, mRNA. }\end{array}$ \\
\hline SLC2A5 & -6.54 & $\begin{array}{l}\text { Homo sapiens solute carrier family } 2 \text { (facilitated glucose/fructose } \\
\text { transporter), member } 5 \text { (SLC2A5), mRNA. }\end{array}$ \\
\hline HSD11B1 & -6.77 & $\begin{array}{l}\text { Homo sapiens hydroxysteroid (11-beta) dehydrogenase } 1 \text { (HSD11B1), } \\
\text { transcript variant } 2 \text {, mRNA. }\end{array}$ \\
\hline CCL5 & -7.10 & Homo sapiens chemokine (C-C motif) ligand 5 (CCL5), mRNA. \\
\hline MYH11 & -7.65 & $\begin{array}{l}\text { Homo sapiens myosin, heavy chain 11, smooth muscle (MYH11), transcript } \\
\text { variant SM1A, mRNA. }\end{array}$ \\
\hline HSD11B1 & -7.87 & $\begin{array}{l}\text { Homo sapiens hydroxysteroid (11-beta) dehydrogenase } 1 \text { (HSD11B1), } \\
\text { transcript variant } 1 \text {, mRNA. }\end{array}$ \\
\hline CD74 & -8.00 & $\begin{array}{l}\text { Homo sapiens CD74 molecule, major histocompatibility complex, class II } \\
\text { invariant chain (CD74), transcript variant } 1 \text {, mRNA. }\end{array}$ \\
\hline CCL5 & -10.74 & Homo sapiens chemokine (C-C motif) ligand 5 (CCL5), mRNA. \\
\hline
\end{tabular}

Further analysis showed that the bioactivity of theEOB significantly overlapped with many canonical pathways from the literature-validated database (Figure 2). Many of these signaling pathways are closely related to the inflammatory, immunomodulatory, and wound healing processes, as well as cancer signaling in human cells. For American Research Journal of Dermatology

Page 13 
Biological Activity of an Essential Oil Blend in Human Dermal Fibroblasts

example, the top two matched pathways werehepatic fibrosis activation and antigen presentation. The robust inhibitory effect of the EOB on these four pathways and genes support its inflammatory and immunomodulatory properties (Tables S3-S6). The observation that the EOB significantly affected pathways related to DNA damage response and cell cycle control (e.g., mitotic roles of the polo-like kinase, cyclins, and cell cycle regulation) suggests thatthe EOB may have an effect oncancer biology and signaling (Figure 2).

Table S3. Top 20 genes regulated by EOB in the Hepatic Fibrosis/Hepatic Stellate Cell Activation canonical path way. Fold change over vehicle is shown as a log2 ratio.

\begin{tabular}{|c|c|c|c|c|c|c|}
\hline $\begin{array}{l}\text { Gene } \\
\text { Symbol }\end{array}$ & Entrez Gene Name & $\begin{array}{l}\text { Illumina } \\
\text { Probe ID }\end{array}$ & Location & Protein Type & $\begin{array}{l}\text { Entrez Gene ID for } \\
\text { Human }\end{array}$ & $\begin{array}{l}\text { Fold Change } \\
\text { Over Vehicle }\end{array}$ \\
\hline TGFB3 & $\begin{array}{l}\text { transforming growth factor, } \\
\text { beta } 3\end{array}$ & ILMN_1687652 & $\begin{array}{l}\text { Extracellular } \\
\text { Space }\end{array}$ & growth factor & 7043 & 1.666 \\
\hline MYL5 & $\begin{array}{l}\text { myosin, light chain } 5 \text {, } \\
\text { regulatory }\end{array}$ & ILMN_2203588 & Cytoplasm & other & 4636 & 1.644 \\
\hline TIMP2 & $\begin{array}{l}\text { TIMP metallopeptidase } \\
\text { inhibitor } 2\end{array}$ & ILMN_1721876 & $\begin{array}{l}\text { Extracellular } \\
\text { Space }\end{array}$ & other & 7077 & -1.608 \\
\hline $\mathrm{A} 2 \mathrm{M}$ & alpha-2-macroglobulin & ILMN_1745607 & $\begin{array}{l}\text { Extracellular } \\
\text { Space }\end{array}$ & transporter & 2 & -1.650 \\
\hline COL6A3 & collagen, type VI, alpha 3 & ILMN_2307861 & $\begin{array}{l}\text { Extracellular } \\
\text { Space }\end{array}$ & other & 1293 & -1.677 \\
\hline CD40 & $\begin{array}{l}\text { CD40 molecule, TNF receptor } \\
\text { superfamily member } 5\end{array}$ & ILMN_1779257 & $\begin{array}{l}\text { Plasma } \\
\text { Membrane }\end{array}$ & $\begin{array}{l}\text { transmembrane } \\
\text { receptor }\end{array}$ & 958 & -1.715 \\
\hline COL18A1 & collagen, type XVIII, alpha 1 & ILMN_1806733 & $\begin{array}{l}\text { Extracellular } \\
\text { Space }\end{array}$ & other & 80781 & -1.840 \\
\hline EDNRA & endothelin receptor type A & ILMN_1796629 & $\begin{array}{l}\text { Plasma } \\
\text { Membrane }\end{array}$ & $\begin{array}{l}\text { transmembrane } \\
\text { receptor }\end{array}$ & 1909 & -1.883 \\
\hline EDNRB & endothelin receptor type B & ILMN_1751904 & $\begin{array}{l}\text { Plasma } \\
\text { Membrane }\end{array}$ & $\begin{array}{l}\text { G-protein } \\
\text { coupled } \\
\text { receptor }\end{array}$ & 1910 & -1.909 \\
\hline COL1A2 & collagen, type I, alpha 2 & ILMN_1785272 & $\begin{array}{l}\text { Extracellular } \\
\text { Space }\end{array}$ & other & 1278 & -1.992 \\
\hline IGFBP3 & $\begin{array}{l}\text { insulin-like growth factor } \\
\text { binding protein } 3\end{array}$ & ILMN_1746085 & $\begin{array}{l}\text { Extracellular } \\
\text { Space }\end{array}$ & other & 3486 & -2.035 \\
\hline MYH10 & $\begin{array}{l}\text { myosin, heavy chain } 10, \text { non- } \\
\text { muscle }\end{array}$ & ILMN_1815154 & Cytoplasm & other & 4628 & -2.036 \\
\hline COL4A2 & collagen, type IV, alpha 2 & ILMN_1724994 & $\begin{array}{l}\text { Extracellular } \\
\text { Space }\end{array}$ & other & 1284 & -2.102 \\
\hline IGFBP5 & $\begin{array}{l}\text { insulin-like growth factor } \\
\text { binding protein } 5\end{array}$ & ILMN_2132982 & $\begin{array}{l}\text { Extracellular } \\
\text { Space }\end{array}$ & other & 3488 & -2.216 \\
\hline CXCL9 & $\begin{array}{l}\text { chemokine (C-X-C motif) } \\
\text { ligand } 9\end{array}$ & ILMN_1745356 & $\begin{array}{l}\text { Extracellular } \\
\text { Space }\end{array}$ & cytokine & 4283 & -2.292 \\
\hline IL1A & interleukin 1, alpha & ILMN_1658483 & $\begin{array}{l}\text { Extracellular } \\
\text { Space }\end{array}$ & cytokine & 3552 & -2.550 \\
\hline MMP9 & matrix metallopeptidase 9 & ILMN_1796316 & $\begin{array}{l}\text { Extracellular } \\
\text { Space }\end{array}$ & peptidase & 4318 & -2.653 \\
\hline VCAM1 & $\begin{array}{l}\text { vascular cell adhesion } \\
\text { molecule } 1\end{array}$ & ILMN_2307903 & $\begin{array}{l}\text { Plasma } \\
\text { Membrane }\end{array}$ & $\begin{array}{l}\text { transmembrane } \\
\text { receptor }\end{array}$ & 7412 & -4.670 \\
\hline MYH11 & $\begin{array}{l}\text { myosin, heavy chain } 11 \text {, } \\
\text { smooth muscle }\end{array}$ & ILMN_1660086 & Cytoplasm & other & 4629 & -7.654 \\
\hline CCL5 & $\begin{array}{l}\text { chemokine (C-C motif) ligand } \\
5\end{array}$ & ILMN_1773352 & $\begin{array}{l}\text { Extracellular } \\
\text { Space }\end{array}$ & cytokine & 6352 & -10.744 \\
\hline
\end{tabular}


Biological Activity of an Essential Oil Blend in Human Dermal Fibroblasts

Table S4. Top 20 genes regulated by EOB in the Antigen Presentation canonical pathway. Fold change over vehicle is shown as a $\log 2$ ratio.

\begin{tabular}{|c|c|c|c|c|c|c|}
\hline $\begin{array}{l}\text { Gene } \\
\text { Symbol }\end{array}$ & Entrez Gene Name & $\begin{array}{l}\text { Illumina } \\
\text { Probe ID }\end{array}$ & Location & Protein Type & $\begin{array}{l}\text { Entrez Gene ID for } \\
\text { Human }\end{array}$ & $\begin{array}{l}\text { Fold Change } \\
\text { Over Vehicle }\end{array}$ \\
\hline PSMB8 & $\begin{array}{l}\text { proteasome (prosome, } \\
\text { macropain) subunit, beta } \\
\text { type, } 8\end{array}$ & ILMN_2284794 & Cytoplasm & peptidase & 5696 & -1.278 \\
\hline IFNG & interferon, gamma & ILMN_2207291 & $\begin{array}{l}\text { Extracellular } \\
\text { Space }\end{array}$ & cytokine & 3458 & -1.305 \\
\hline HLA-C & $\begin{array}{l}\text { major histocompatibility } \\
\text { complex, class I, C }\end{array}$ & ILMN_1721113 & $\begin{array}{l}\text { Plasma } \\
\text { Membrane }\end{array}$ & other & 3107 & -1.449 \\
\hline HLA-DQA1 & $\begin{array}{l}\text { major histocompatibility } \\
\text { complex, class II, DQ alpha } 1\end{array}$ & ILMN_1808405 & $\begin{array}{l}\text { Plasma } \\
\text { Membrane }\end{array}$ & $\begin{array}{l}\text { transmembrane } \\
\text { receptor }\end{array}$ & 3117 & -1.485 \\
\hline PSMB9 & $\begin{array}{l}\text { proteasome (prosome, } \\
\text { macropain) subunit, beta } \\
\text { type, } 9\end{array}$ & ILMN_2376108 & Cytoplasm & peptidase & 5698 & -1.491 \\
\hline HLA-DOA & $\begin{array}{l}\text { major histocompatibility } \\
\text { complex, class II, DO alpha }\end{array}$ & ILMN_1659075 & $\begin{array}{l}\text { Plasma } \\
\text { Membrane }\end{array}$ & $\begin{array}{l}\text { transmembrane } \\
\text { receptor }\end{array}$ & 3111 & -1.498 \\
\hline HLA-G & $\begin{array}{l}\text { major histocompatibility } \\
\text { complex, class I, G }\end{array}$ & ILMN_1656670 & $\begin{array}{l}\text { Plasma } \\
\text { Membrane }\end{array}$ & other & 3135 & -1.598 \\
\hline HLA-B & $\begin{array}{l}\text { major histocompatibility } \\
\text { complex, class I, B }\end{array}$ & ILMN_1778401 & $\begin{array}{l}\text { Plasma } \\
\text { Membrane }\end{array}$ & $\begin{array}{l}\text { transmembrane } \\
\text { receptor }\end{array}$ & 3106 & -1.612 \\
\hline HLA-A & $\begin{array}{l}\text { major histocompatibility } \\
\text { complex, class I, A }\end{array}$ & ILMN_2165753 & $\begin{array}{l}\text { Plasma } \\
\text { Membrane }\end{array}$ & other & 3105 & -1.681 \\
\hline MR1 & $\begin{array}{l}\text { major histocompatibility } \\
\text { complex, class I-related }\end{array}$ & ILMN_2167416 & $\begin{array}{l}\text { Plasma } \\
\text { Membrane } \\
\end{array}$ & $\begin{array}{l}\text { transmembrane } \\
\text { receptor }\end{array}$ & 3140 & -1.697 \\
\hline TAPBP & TAP binding protein (tapasin) & ILMN_1742450 & Cytoplasm & transporter & 6892 & -1.722 \\
\hline HLA-DMA & $\begin{array}{l}\text { major histocompatibility } \\
\text { complex, class II, DM alpha }\end{array}$ & ILMN_1695311 & $\begin{array}{l}\text { Plasma } \\
\text { Membrane }\end{array}$ & $\begin{array}{l}\text { transmembrane } \\
\text { receptor }\end{array}$ & 3108 & -2.036 \\
\hline HLA-DMB & $\begin{array}{l}\text { major histocompatibility } \\
\text { complex, class II, DM beta }\end{array}$ & ILMN_1761733 & $\begin{array}{l}\text { Plasma } \\
\text { Membrane }\end{array}$ & $\begin{array}{l}\text { transmembrane } \\
\text { receptor }\end{array}$ & 3109 & -2.045 \\
\hline HLA-DRB5 & $\begin{array}{l}\text { major histocompatibility } \\
\text { complex, class II, DR beta } 5\end{array}$ & ILMN_1697499 & $\begin{array}{l}\text { Plasma } \\
\text { Membrane }\end{array}$ & $\begin{array}{l}\text { transmembrane } \\
\text { receptor }\end{array}$ & 3127 & -2.116 \\
\hline HLA-F & $\begin{array}{l}\text { major histocompatibility } \\
\text { complex, class I, F }\end{array}$ & ILMN_1762861 & $\begin{array}{l}\text { Plasma } \\
\text { Membrane } \\
\end{array}$ & $\begin{array}{l}\text { transmembrane } \\
\text { receptor }\end{array}$ & 3134 & -2.402 \\
\hline HLA-DPA1 & $\begin{array}{l}\text { major histocompatibility } \\
\text { complex, class II, DP alpha } 1\end{array}$ & ILMN_1772218 & $\begin{array}{l}\text { Plasma } \\
\text { Membrane }\end{array}$ & $\begin{array}{l}\text { transmembrane } \\
\text { receptor }\end{array}$ & 3113 & -3.037 \\
\hline HLA-DRB4 & $\begin{array}{l}\text { major histocompatibility } \\
\text { complex, class II, DR beta } 4\end{array}$ & ILMN_1752592 & $\begin{array}{l}\text { Plasma } \\
\text { Membrane }\end{array}$ & $\begin{array}{l}\text { transmembrane } \\
\text { receptor }\end{array}$ & 3126 & -3.370 \\
\hline HLA-DRB1 & $\begin{array}{l}\text { major histocompatibility } \\
\text { complex, class II, DR beta } 1\end{array}$ & ILMN_3228688 & $\begin{array}{l}\text { Plasma } \\
\text { Membrane }\end{array}$ & $\begin{array}{l}\text { transmembrane } \\
\text { receptor }\end{array}$ & 3123 & -4.415 \\
\hline HLA-DRA & $\begin{array}{l}\text { major histocompatibility } \\
\text { complex, class II, DR alpha }\end{array}$ & ILMN_2157441 & $\begin{array}{l}\text { Plasma } \\
\text { Membrane }\end{array}$ & $\begin{array}{l}\text { transmembrane } \\
\text { receptor }\end{array}$ & 3122 & -4.696 \\
\hline CD74 & $\begin{array}{l}\text { CD74 molecule, major } \\
\text { histocompatibility complex, } \\
\text { class II invariant chain }\end{array}$ & ILMN_1736567 & $\begin{array}{l}\text { Plasma } \\
\text { Membrane }\end{array}$ & $\begin{array}{l}\text { transmembrane } \\
\text { receptor }\end{array}$ & 972 & -7.999 \\
\hline
\end{tabular}


Biological Activity of an Essential Oil Blend in Human Dermal Fibroblasts

Table S5. Top 20 genes regulated by EOB in the Mitotic Roles of Polo-Like Kinase canonical pathway. Fold change over vehicle is shown as a $\log 2$ ratio.

\begin{tabular}{|c|c|c|c|c|c|c|}
\hline $\begin{array}{l}\text { Gene } \\
\text { Symbol }\end{array}$ & Entrez Gene Name & $\begin{array}{l}\text { Illumina } \\
\text { Probe ID }\end{array}$ & Location & Protein Type & $\begin{array}{c}\text { Entrez Gene ID for } \\
\text { Human }\end{array}$ & $\begin{array}{l}\text { Fold Change } \\
\text { Over Vehicle }\end{array}$ \\
\hline FZR1 & $\begin{array}{l}\text { fizzy/cell division cycle } 20 \\
\text { related } 1 \text { (Drosophila) }\end{array}$ & ILMN_3306993 & Nucleus & kinase & 51343 & 1.389 \\
\hline PPP2R2A & $\begin{array}{l}\text { protein phosphatase } 2 \text {, } \\
\text { regulatory subunit B, alpha }\end{array}$ & ILMN_1788961 & Cytoplasm & phosphatase & 5520 & 1.330 \\
\hline RAD21 & RAD21 homolog (S. pombe) & ILMN_1748578 & Nucleus & other & 5885 & -1.352 \\
\hline CCNB3 & cyclin B3 & ILMN_1705757 & Nucleus & other & 85417 & -1.361 \\
\hline PPP2R4 & $\begin{array}{l}\text { protein phosphatase } 2 \mathrm{~A} \\
\text { activator, regulatory subunit } \\
4\end{array}$ & ILMN_1658951 & Cytoplasm & phosphatase & 5524 & -1.371 \\
\hline PTTG1 & $\begin{array}{l}\text { pituitary tumor-transforming } \\
1\end{array}$ & ILMN_2042771 & Nucleus & $\begin{array}{l}\text { transcription } \\
\text { regulator }\end{array}$ & 9232 & -1.407 \\
\hline PPP2R3B & $\begin{array}{l}\text { protein phosphatase } 2, \\
\text { regulatory subunit B", beta }\end{array}$ & ILMN_1712257 & Nucleus & phosphatase & 28227 & -1.411 \\
\hline PKMYT1 & $\begin{array}{l}\text { protein kinase, membrane } \\
\text { associated } \\
\text { tyrosine/threonine } 1\end{array}$ & ILMN_2401436 & Cytoplasm & kinase & 9088 & -1.414 \\
\hline WEE1 & WEE1 G2 checkpoint kinase & ILMN_1778561 & Nucleus & kinase & 7465 & -1.470 \\
\hline PLK1 & polo-like kinase 1 & ILMN_1736176 & Nucleus & kinase & 5347 & -1.531 \\
\hline CCNB1 & cyclin B1 & ILMN_1712803 & Cytoplasm & kinase & 891 & -1.621 \\
\hline $\mathrm{CDC} 20$ & cell division cycle 20 & ILMN_1663390 & Nucleus & other & 991 & -1.778 \\
\hline FBX05 & F-box protein 5 & ILMN_1710676 & Nucleus & enzyme & 26271 & -1.785 \\
\hline PLK4 & polo-like kinase 4 & ILMN_1789123 & Cytoplasm & kinase & 10733 & -1.849 \\
\hline $\mathrm{CDC} 25 \mathrm{C}$ & cell division cycle $25 \mathrm{C}$ & ILMN_1725260 & Nucleus & phosphatase & 995 & -1.905 \\
\hline KIF23 & kinesin family member 23 & ILMN_1811472 & Cytoplasm & other & 9493 & -2.166 \\
\hline CCNB2 & cyclin B2 & ILMN_1801939 & Cytoplasm & other & 9133 & -2.398 \\
\hline KIF11 & kinesin family member 11 & ILMN_2143155 & Nucleus & other & 3832 & -2.987 \\
\hline CDK1 & cyclin-dependent kinase 1 & ILMN_1747911 & Nucleus & kinase & 983 & -3.065 \\
\hline PRC1 & $\begin{array}{l}\text { protein regulator of } \\
\text { cytokinesis } 1\end{array}$ & ILMN_1728934 & Nucleus & other & 9055 & -3.664 \\
\hline
\end{tabular}

American Research Journal of Dermatology 
Biological Activity of an Essential Oil Blend in Human Dermal Fibroblasts

Table S6. Top 20 genes regulated by EOB in the Cyclins and Cell Cycle Regulation canonical pathway. Fold change over vehicle is shown as a $\log 2$ ratio.

\begin{tabular}{|c|c|c|c|c|c|c|}
\hline $\begin{array}{l}\text { Gene } \\
\text { Symbol }\end{array}$ & Entrez Gene Name & $\begin{array}{l}\text { Illumina } \\
\text { Probe ID }\end{array}$ & Location & Protein Type & $\begin{array}{c}\text { Entrez Gene ID for } \\
\text { Human }\end{array}$ & $\begin{array}{l}\text { Fold Change } \\
\text { Over Vehicle }\end{array}$ \\
\hline E2F5 & $\begin{array}{l}\text { E2F transcription factor } 5 \text {, } \\
\text { p130-binding }\end{array}$ & ILMN_1782551 & Nucleus & $\begin{array}{l}\text { transcription } \\
\text { regulator }\end{array}$ & 1875 & 1.901 \\
\hline TGFB3 & $\begin{array}{l}\text { transforming growth factor, } \\
\text { beta } 3\end{array}$ & ILMN_1687652 & $\begin{array}{l}\text { Extracellular } \\
\text { Space }\end{array}$ & growth factor & 7043 & 1.666 \\
\hline PA2G4 & $\begin{array}{l}\text { proliferation-associated 2G4, } \\
38 \mathrm{kDa}\end{array}$ & ILMN_1728984 & Nucleus & $\begin{array}{l}\text { transcription } \\
\text { regulator }\end{array}$ & 5036 & 1.395 \\
\hline CDKN2C & $\begin{array}{l}\text { cyclin-dependent kinase } \\
\text { inhibitor } 2 \mathrm{C} \text { (p18, inhibits } \\
\text { CDK4) }\end{array}$ & ILMN_2359332 & Nucleus & $\begin{array}{l}\text { transcription } \\
\text { regulator }\end{array}$ & 1031 & 1.387 \\
\hline HDAC2 & histone deacetylase 2 & ILMN_1767747 & Nucleus & $\begin{array}{l}\text { transcription } \\
\text { regulator }\end{array}$ & 3066 & 1.337 \\
\hline PPP2R2A & $\begin{array}{l}\text { protein phosphatase } 2, \\
\text { regulatory subunit B, alpha }\end{array}$ & ILMN_1788961 & Cytoplasm & phosphatase & 5520 & 1.330 \\
\hline CCNB3 & cyclin B3 & ILMN_1705757 & Nucleus & other & 85417 & -1.361 \\
\hline CDK2 & cyclin-dependent kinase 2 & ILMN_1665559 & Nucleus & kinase & 1017 & -1.368 \\
\hline PPP2R4 & $\begin{array}{l}\text { protein phosphatase } 2 \mathrm{~A} \\
\text { activator, regulatory subunit } \\
4\end{array}$ & ILMN_1658951 & Cytoplasm & phosphatase & 5524 & -1.371 \\
\hline PPP2R3B & $\begin{array}{l}\text { protein phosphatase } 2 \text {, } \\
\text { regulatory subunit B", beta }\end{array}$ & ILMN_1712257 & Nucleus & phosphatase & 28227 & -1.411 \\
\hline RB1 & retinoblastoma 1 & ILMN_1696591 & Nucleus & $\begin{array}{l}\text { transcription } \\
\text { regulator }\end{array}$ & 5925 & -1.411 \\
\hline E2F2 & E2F transcription factor 2 & ILMN_1777233 & Nucleus & $\begin{array}{l}\text { transcription } \\
\text { regulator }\end{array}$ & 1870 & -1.444 \\
\hline WEE1 & WEE1 G2 checkpoint kinase & ILMN_1778561 & Nucleus & kinase & 7465 & -1.470 \\
\hline CDKN1B & $\begin{array}{l}\text { cyclin-dependent kinase } \\
\text { inhibitor 1B (p27, Kip1) }\end{array}$ & ILMN_2196347 & Nucleus & kinase & 1027 & -1.479 \\
\hline CCNB1 & cyclin B1 & ILMN_1712803 & Cytoplasm & kinase & 891 & -1.621 \\
\hline CDKN2B & $\begin{array}{l}\text { cyclin-dependent kinase } \\
\text { inhibitor } 2 \mathrm{~B} \text { ( } 15 \text {, inhibits } \\
\text { CDK4) }\end{array}$ & ILMN_2376723 & Nucleus & $\begin{array}{l}\text { transcription } \\
\text { regulator }\end{array}$ & 1030 & -1.766 \\
\hline CCNE2 & cyclin E2 & ILMN_2412384 & Nucleus & other & 9134 & -1.827 \\
\hline CCNA2 & cyclin A2 & ILMN_1786125 & Nucleus & other & 890 & -2.088 \\
\hline CCNB2 & cyclin B2 & ILMN_1801939 & Cytoplasm & other & 9133 & -2.398 \\
\hline CDK1 & cyclin-dependent kinase 1 & ILMN_1747911 & Nucleus & kinase & 983 & -3.065 \\
\hline
\end{tabular}


Biological Activity of an Essential Oil Blend in Human Dermal Fibroblasts

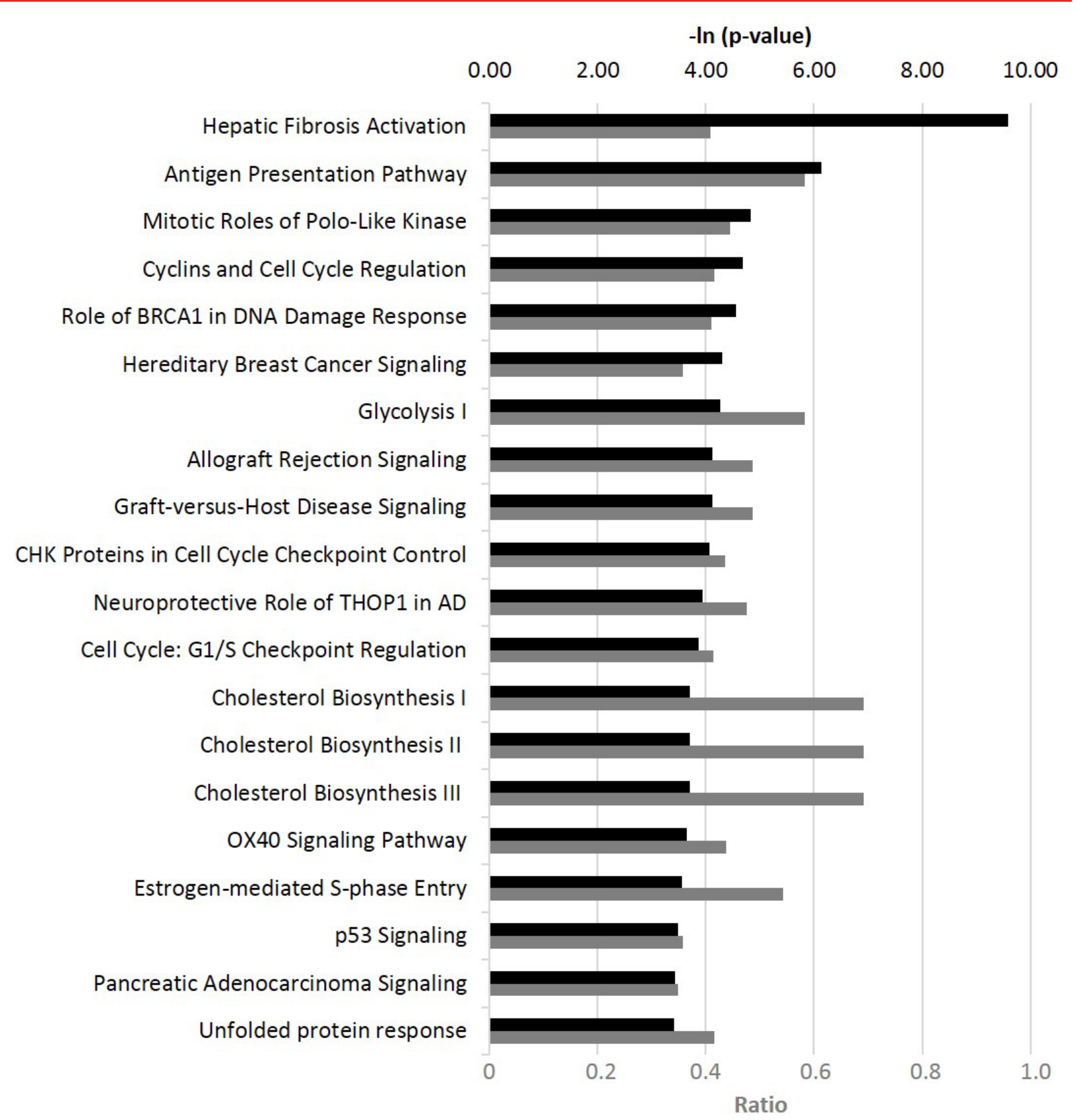

Fig2. Top 20 canonical pathways matching the bioactivity profile of the essential oil blend (EOB, $0.0033 \% \mathrm{v} / \mathrm{v}$ ) in gene expression in an HDF3CGF system, produced using Ingenuity Pathway Analysis (IPA). Each p-value was calculated using the right-tailed Fisher's exact test. The p-value measures the likelihood that the observed association between a specific pathway and the dataset is due to random chance. Pathways with smaller p-values (bigger - In [p-values], indicated by the black bars) matched the bioactivity of the EOB more significantly than those with higher values did. A ratio, indicated by each gray bar, was calculated by taking the number of genes from the EOB dataset that participate in a canonical pathway and dividing it by the total number of genes in that pathway. BRCA1, human breast cancer gene 1; THOP1, thimetoligopeptidase; AD, Alzheimer's disease; OX40 (TNFRSF4), tumor necrosis factor receptor superfamily, member 4; p53, tumor suppressor protein 53 
These results are also consistent with findings of other research studies on the biological activity of the primary chemical constituents of the EOB. For example, limonene inhibited the expression of a number of inflammatory genes in an osteoarthritis model (Rufino et al., 2015) and $\alpha$-pinene affected immunomodulatory genes in a mouse model of allergic rhinitis (Nam et al., 2014). Eugenol, the third most abundant constituent in the EOB, is known for its anti-cancer and anti-inflammatory properties in various cell types. It has been shown to upregulate genes in the base excision repair pathway (Ghosh et al., 2005) while downregulating inflammatory cytokines (Pal et al., 2010) and antiapoptotic genes (Kaur et al., 2010).

This study provides important data on the biological activity of an EOB in cytokine-stimulated human dermal fibroblasts. The data suggest that the EOB may modulate inflammatory and immune responses, tissue remodeling, and cancer signaling processes in a manner unique to any individualoil studied previously. Further research is needed to elucidate the biological and physiological mechanisms of action of the EOB and any synergistic or antagonistic interactions between the compounds contained therein.

\section{CONCLUSIONS}

To the best of our knowledge, this is the first study to analyze the effect of an EOB on genome-wide gene expression in human skin cells. The EOBsignificantly modulated mRNA levelsof genes involved in a variety of important signaling pathways including inflammation, immune function, wound healing, cell cycle regulation, and DNA damage repair. It's biological activity is unique to any pure essential oil studied previously. This study providesoriginal and important data onthemodulation ofgenome-wide gene expression in validated human cell cultures by an essential oil blend.Finally, theseresults suggest that this EOB maypossess the potential to modulate inflammatory and immune responses in skin cells, giving it practical applications in the fields of dermatology and medicine in general.

\section{ACKNOWLEDGMENT}

This study was funded by dōTERRA (Pleasant Grove, UT, USA) and conducted at DiscoverX (Fremont, CA, USA). Xuesheng Han, Ph.D. designed the study, analyzed the data, and wrote the paper. Tyler Bahr, B. S. participated in writing the paper. The authors would like to acknowledge Carsten Smidt, Ph.D.; Tory Parker, Ph.D.; Cody Beaumont, Ph.D.; Jeff Dorsett, M.S.; and Nicole Stevens, M.S. for their support to the work.

\section{Competing Interest}

Xuesheng Han and Tyler Bahr are employees of dōTERRA, where the studied agent EOB was manufactured.

\section{REFERENCES}

1. Barbosa-Morais, N. L., Dunning, M. J., Samarajiwa, S. A., Darot, J. F. J., Ritchie, M. E., Lynch, A. G., \& Tavaré, S. (2010). A re-annotation pipeline for Illumina BeadArrays: improving the interpretation of gene expression data. Nucleic Acids Research, 38(3), e17. https://doi.org/10.1093/nar/gkp942

2. Berg, E. L., Yang, J., Melrose, J., Nguyen, D., Privat, S., Rosler, E., \&Ekins, S. (2010). Chemical target and pathway toxicity mechanisms defined in primary human cell systems. Journal of Pharmacological and Toxicological Methods, 61(1), 3-15. https://doi.org/10.1016/j.vascn.2009.10.001

3. Bergamini, G., Bell, K., Shimamura, S., Werner, T., Cansfield, A., Müller, K., \&Neubauer, G. (2012). A selective inhibitor reveals PI3K $\gamma$ dependence of T(H)17 cell differentiation. Nature Chemical Biology, 8(6), 576-582. https://doi.org/10.1038/nchembio.957

4. Bolstad, B. M., Irizarry, R. A., Astrand, M., \& Speed, T. P. (2003). A comparison of normalization methods for high density oligonucleotide array data based on variance and bias. Bioinformatics (Oxford, England), 19(2), 185-193. 
Biological Activity of an Essential Oil Blend in Human Dermal Fibroblasts

5. Chaudhary, S. C., Siddiqui, M. S., Athar, M., \& Alam, M. S. (2012). D-Limonene modulates inflammation, oxidative stress and Ras-ERK pathway to inhibit murine skin tumorigenesis. Human \& Experimental Toxicology, 31(8), 798-811. https://doi.org/10.1177/0960327111434948

6. Dunning, M. J., Smith, M. L., Ritchie, M. E., \& Tavaré, S. (2007). beadarray: R classes and methods for Illumina bead-based data. Bioinformatics (Oxford, England), 23(16), 2183-2184. https://doi.org/10.1093/ bioinformatics/btm311

7. Ghosh, R., Nadiminty, N., Fitzpatrick, J. E., Alworth, W. L., Slaga, T. J., \& Kumar, A. P. (2004). Eugenol causes melanoma growth suppression through inhibition of E2F1 transcriptional activity. Journal of Biological Chemistry, 280(7), 5812-5819. doi:10.1074/jbc.m411429200

8. Han, X., \& Parker, T. L. (2017a). Anti-inflammatory activity of Juniper (Juniperus communis) berry essential oil in human dermal fibroblasts. Cogent Medicine, 4(1), 1306200. https://doi.org/10.1080/2331205X.201 7.1306200

9. Han, X., \& Parker, T. L. (2017b). Anti-inflammatory, tissue remodeling, immunomodulatory, and anticancer activities of oregano (Origanum vulgare) essential oil in a human skin disease model. Biochimie Open, 4, 73-77. https://doi.org/10.1016/j.biopen.2017.02.005

10. Han, X., \& Parker, T. L. (2017c). Biological activities of frankincense essential oil in human dermal fibroblasts. Biochimie Open, 4, 31-35. doi:10.1016/j.biopen.2017.01.003

11. Han, X., \& Parker, T. L. (2017d). Anti-inflammatory activity of clove (Eugenia caryophyllata) in human dermal fibroblasts. Pharm Biol., 55(1), 1619-1622. https://doi.org/10.1080/13880209.2017.1314513

12. Han, X., Price, R., \& Parker, T. L. (2017). An essential oil blend modulates important inflammation- and immune response-related biomarkers in human cell cocultures. Cogent Medicine, $0(\mathrm{ja}), 1302909$. https:// doi.org/10.1080/2331205X.2017.1302909

13. Hąc-Wydro, K., Flasiński, M., Broniatowski, M., \& Sołtys, M. (2017). Studies on the Behavior of Eucalyptol and Terpinen-4-ol—Natural Food Additives and Ecological Pesticides-in Model Lipid Membranes. Langmuir, 33(27), 6916-6924. doi:10.1021/acs.langmuir.7b00774

14. Kaur, G., Athar, M., \& Alam, M. S. (2009). Eugenol precludes cutaneous chemical carcinogenesis in mouse by preventing oxidative stress and inflammation and by inducing apoptosis. Molecular Carcinogenesis,49(3), 290-301. doi:10.1002/mc.20601

15. Kim, D., Lee, H., Jeon, Y., Han, Y., Kee, J., Kim, H., \& Hong, S. (2015). Alpha-pinene exhibits anti-inflammatory activity through the suppression of MAPKs and the NF- $\mathrm{KB}$ pathway in mouse peritoneal macrophages. The American Journal of Chinese Medicine, 43(04), 731-742. doi:10.1142/s0192415×15500457

16. Kozioł, A., Stryjewska, A., Librowski, T., Sałat, K., Gaweł, M., Moniczewski, A., \& Lochyński, S. (2014). An overview of the pharmacological properties and potential applications of natural monoterpenes. Mini Reviews in Medicinal Chemistry, 14(14), 1156-1168.

17. Kunkel, E. J., Plavec, I., Nguyen, D., Melrose, J., Rosler, E. S., Kao, L. T., ... Berg, E. L. (2004). Rapid structure-activity and selectivity analysis of kinase inhibitors by BioMAP analysis in complex human primary cell-based models. Assay and Drug Development Technologies, 2(4), 431-441. https://doi. org/10.1089/adt.2004.2.431

18. Lv, X. N., Liu, Z. J., Zhang, H. J., \& Tzeng, C. M. (2013). Aromatherapy and the central nerve system (CNS): therapeutic mechanism and its associated genes. Current Drug Targets, 14(8), 872-879. 
19. Nam, S., Chung, C., Seo, J., Rah, S., Kim, H., \& Jeong, H. (2014). The therapeutic efficacy of $\alpha$-pinene in an experimental mouse model of allergic rhinitis. International Immunopharmacology, 23(1), 273-282. doi:10.1016/j.intimp.2014.09.010

20. Navarra, M., Mannucci, C., Delbò, M., \& Calapai, G. (2015). Citrus bergamia essential oil: from basic research to clinical application. Frontiers in Pharmacology, 6, 36. https://doi.org/10.3389/fphar.2015.00036

21. Pal, D., Banerjee, S., Mukherjee, S., Roy, A., Panda, C. K., \& Das, S. (2010). Eugenol restricts DMBA croton oil induced skin carcinogenesis in mice: Downregulation of c-Myc and H-ras, and activation of p53 dependent apoptotic pathway. Journal of Dermatological Science, 59(1), 31-39. doi:10.1016/j.jdermsci.2010.04.013

22. Perry, N., \& Perry, E. (2006). Aromatherapy in the management of psychiatric disorders: clinical and neuropharmacological perspectives. CNS Drugs, 20(4), 257-280.

23. R Development Core Team. (2011). R: A language and environment for statistical computing. Vienna, Austria: the R Foundation for Statistical Computing. Retrieved from http://www.R-project.org/

24. Rehman, M. U., Tahir, M., Khan, A. Q., Khan, R., O., Lateef, A., \& Sultana, S. (2014). D-limonene suppresses doxorubicin-induced oxidative stress and inflammation via repression of COX-2, iNOS, and NFKB in kidneys of Wistar rats. Experimental Biology and Medicine, 239(4), 465-476. doi:10.1177/1535370213520112

25. Rufino, A. T., Ribeiro, M., Sousa, C., Judas, F., Salgueiro, L., Cavaleiro, C., \& Mendes, A. F. (2015). Evaluation of the anti-inflammatory, anti-catabolic and pro-anabolic effects of E-caryophyllene, myrcene and limonene in a cell model of osteoarthritis. Europeanjournal of Pharmacology, 750, 141-150. doi:10.1016/j. ejphar.2015.01.018

26. Yoon, W.-J., Lee, N. H., \& Hyun, C.-G. (2010). Limonene suppresses lipopolysaccharide-induced production of nitric oxide, prostaglandin E2, and pro-inflammatory cytokines in RAW 264.7 macrophages. Journal of Oleo Science, 59(8), 415-421.

27. Zhou, J., Tang, F., Mao, G., \& Bian, R. (2004). Effect of alpha-pinene on nuclear translocation of NF-kappa B in THP-1 cells. Acta Pharmacologica Sinica, 25(4), 480-484.

Citation: Xuesheng Han, Tyler Bahr, "Biological Activity of an Essential Oil Blend in Human Dermal Fibroblasts". American Research Journal of Dermatology. 1(1): 1-21.

Copyright (C) Xuesheng Han, Tyler Bahr, This is an open access article distributed under the Creative Commons Attribution License, which permits unrestricted use, distribution, and reproduction in any medium, provided the original work is properly cited. 